\title{
Research on English Translation of Chinese Contemporary Literature
}

\author{
Zheng Chao \\ Xijing University, Xi'an, Shaanxi, 710100
}

Keywords: Chinese Contemporary Literature, English Translation, Hot Topic

\begin{abstract}
The study of English translation of Chinese literature currently presents the characteristics of both macro and micro, both broad and diverse, classical and contemporary, and the normative nature of research. Of course, while seeing its gratifying side, it cannot ignore the problems such as low academic consciousness, serious follow-up phenomenon, and partial rudeness of some papers. Only by seeing the results, facing the problems and responding positively, the study of English translation of Chinese literature can develop healthily and truly point out the direction and path for Chinese literature and culture to go out.
\end{abstract}

\section{Introduction}

As China's global status has increased significantly, Chinese culture has also received increasing attention from people around the world. For the purpose of enhancing exchanges and mutual trust with the countries of the world and expanding the influence of Chinese culture, the Chinese culture has become an issue that needs urgent attention. Therefore, the translation of Chinese literature has become a hot topic. At present, English has become a worldwide language, and the population used is also very extensive. Therefore, the English translation of Chinese literature has become a top priority. The Chinese government has also worked hard and paid a lot of energy and financial resources. In the 1980s and 1990s, the PandaBooks 1 project, edited and published by the famous translator Yang Xianyi, launched 195 literary works. However, the large-scale "Panda Series" did not achieve the expected results. Except for the individual translations that were welcomed by English and American readers, most of the translations did not produce any reaction among them" (Yuqiang 2010: 134). The "Greater China Library" 2 translation project launched since the beginning of the new century is also a huge undertaking. So far, this huge translation project has been published in 178 volumes.

\section{Combination of macro and micro}

The study of English translation of Chinese literature presents a combination of macroscopic "line" and microscopic "point", and the combination of the whole and the part. Taking the English translation of "Dream of Red Mansions" as an example, when a certain period of time is summarized in the English translation of "Dream of Red Mansions", there will be some time-based "English translation history" research, the time span from ten years. 20 years or even 100 years. And there is no shortage of doctoral thesis. The accumulation of "points" is bound to become a precondition for the "line", and the emergence of the "line" has become a summary and reflection of the "point". In addition to this summary of English translation history studies, there are comparative analysis of different translations. For example, the analysis of the translations of Yang Xianyi and Gladys and the translations of Hawkes and Deanford. Whether it is the "English translation history" research or the translation comparison, the English translation of "Dream of Red Mansions" is taken from the macro or the whole. In contrast to this holistic study, the analysis of different parts of the whole body is carried out. The most common is microscopic research from different perspectives. The researchers split the whole of "Dream of Red Mansions" and then break through one by one. For example, the English translation of the chapter back to the title, the study of English translation of poetry and music, the study of English translation of death euphemism, the study of English translation of "idiot", the study of English translation of Chinese cuisine, the study of translation of 
Chinese medicine culture, and the English of relatives Translation studies, comparative analysis of English translation of "words", evaluation of English translation of costumes, etc., are numerous and numerous. The English translation studies of other works also show such characteristics, such as "The English Translation of "Water Margin" in the past 20 years", "Thirty Years of English Translation of the Chinese Water Margin", and "English Translation from the Water Margin" "Looking at the Cultural Exchange between China and the West"; "Translation Strategies of the Two Versions of The Water Margin", "Two English Versions of the Translator's Values Analysis" and "Multi-Dimensional Comparative Study of the Translation Features of the Four English Versions" — Based on the parallel paradigm of research paradigm; "Study on the English translation of Chinese dialect vocabulary in Shui Shuan Chuan", "Study on Idioms in Sha Boli's English Translation", and from the Perspective of Cognitive Linguistics "The Comparative Study of English Translation of Characters in Water Margin" and so on. On the English translation of "The Romance of the Three Kingdoms", the articles on "History of English Translation" include "The Study of English Translation of the Romance of the Three Kingdoms: Comments and Suggestions" and "Review of the English Translation of the Romance of the Three Kingdoms in the Last Ten Years"; The articles on text comparison include "Appreciation of the English Version of The Romance of the Three Kingdoms" and "Comparative Study of Two English Versions of the Romance of the Three Kingdoms" from the Perspective of Skopostheoria; the articles on different parts of the translation are "Romance Translation". English translation of the word capacity and problems, "English translation of the address terms in the "Three Kingdoms" from the perspective of relevance".

\section{Main factors affecting the selection of translation strategies}

The most significant difference in cultural differences between countries is the difference in customs and habits. Customs and habits are formed by the people of a country in the long-term historical precipitation, and the habits and customary behaviors formed in the diet, marriage and burial, costumes, etiquette. A few examples are given to illustrate the influence of the differences between Chinese and foreign customs and habits on the translation process of contemporary Chinese literature. For example, since the May Fourth Movement in China, the country has experienced a long period of turbulence, unhealthy food, and untidy clothes. Therefore, we are now habitually asking the place when we meet. "Are you eating?" This traditional way of saying hello is still in use today. However, in the United Kingdom, for example, in the United Kingdom, due to the warm and humid climate in the UK and the frequent rains and rains, when the British meet each other, the greetings start from talking about the weather. In addition, our wedding is a festive celebration, so we will use a lot of big red elements to arrange the wedding scene, including the bride's dress, while in foreign countries, red symbolizes "blood", "dead", "massacre", "slaughter" and many other bad meanings. Therefore, foreign wedding arrangements are mainly white, and the bride is usually wearing a white gauze, but white is an ominous symbol in China.

Here we compare the geographical and geographical differences between China and the UK. The generation of language is closely related to the productive labor of people of all countries. Many languages are from the initial production activities. Britain is an island country. In history, the British maritime industry has always been in the leading position in the world. China is a country with a relatively large land area and a large sea area. Most of the population lives on land and is a typical agricultural country. The descendants of the Yellow Emperor from generation to generation are inseparable from the land. The different characteristics of these geographical environments are evident in the differences in some languages.

The issue of religious belief is not only a matter of cautious treatment in the process of communication with people in other countries. In the process of translation of Chinese literary works, the choice of words and the expression of sentences must always pay attention to the different religious beliefs of different countries. Most of the religious believers in China are Buddhism, and the tradition of Buddhism has a long history in China. Most of the foreign believers are Christians who believe in God. Therefore, among many literary works in China, there are words 
and sentences related to Buddhism, such as "putting down the butcher knife and setting up a place to become a Buddha”, and there are many words related to God in foreign literary works, such as "God help". Those who helpthemselves". Therefore, when Chinese translators are working on Chinese-English translation of literary works, they rely on the translation of the culture of the country, that is, the cultural characteristics of our country, and translate the slightly obscure and exotic literature with Chinese characteristics. Is the work still based on the culture of translating into the country, that is, the characteristics of foreign cultures, and the translation of literary works that can make foreign readers easy to understand and understand? This inevitably involves the choice of an English translation strategy.

\section{English Translation Strategies of Chinese Contemporary Literature}

The domestication strategy in the translation strategy is the use of very frequent translation techniques. It can also be called free translation, which is based on the central meaning of the words to be understood and integrated into another language. This kind of domestication strategy follows the theory of "dynamic equivalence theory", which requires translators not only to be consistent with the original text in the expression of words and sentences, but also to be able to conform to the language use of the target language countries. Habits are convenient for readers of the target language countries to understand. However, free translation, as the name implies, is mainly about the consistency of the core meaning of the language, so in terms of sentence structure, it is not completely required to be consistent with the structural framework of the original text. The domestication strategy has its advantages and disadvantages. The advantage is that it can streamline and convey the meaning of the original text in another language, which is convenient for the reader to understand and better achieve the purpose of communication between the ideological and cultural exchanges, avoiding the lengthy and cumbersome sentence patterns. It's hard to understand. On the other hand, to a certain extent, the Italian translator will have its own emotional color and personal judgment, and will not be able to completely convey the meaning of the original author, which is easy to mislead the reader, and because of "naturalization" more It is based on the cultural form of the target language country, and it is suspected of welcoming the readers. Instead, it can not let the readers slowly experience the exotic customs and the whole picture, and cast a similar veil on the exchange of international cultures. Conducive to clear insight into the differences between the different cultures.

The alienation strategy is relative to the naturalization strategy and can also be called literal translation. Because of the great differences among cultures in different countries, translators who prefer literal translations are more likely to pursue the language expressions that approach the appearance of the original text in another form. For example, Mr. Zhao Shuli's "Small Two Black Marriage" has a strong local flavor and local color, which truly reflects the social life of the rural areas in Shanxi and the spiritual outlook of the peasants. There are many culturally loaded words in this article, and culturally-loaded words refer to words, phrases, and idioms that have significant Chinese national characteristics, traditions, and history. Taking the translation of this article as an example, there is a certain controversy in adopting the domestication strategy or the alienation strategy. The author believes that for this kind of local novels with obvious regional characteristics and cultural and historical traditions, the alienation strategy of literal translation can show the author's humorous, funny, vivid and vivid language style. It also needs a group of true love. Chinese culture, readers who want to understand the essence of Chinese culture. If this article adopts the naturalized translation strategy, although it can absorb more readers, it is more easy to understand, but it loses the essence of the original itself, adds the foreign gas, but loses the most fascinating local flavor, and this is also The soul of the work. In addition, many writers in China's new era have received new education and have a thorough understanding of foreign cultures. In their own works of literary creation, they have shown many elements of foreign internationalization. Some languages are used. Globally, it is not proprietary to a country. Therefore, under the current situation of cultural exchanges, frequent language exchanges, and increased foreign vocabulary, the foreignization translation strategy is a better choice. 


\section{Conclusion}

Many outstanding literary works are deeply rooted in their national history, culture and language. No matter how familiar the translator is to the language of translation and how skilled the translation skills are, it is difficult to guarantee that the readers will have the same or similar reading experience as the source readers. Therefore, for the status quo of some excellent local works being cold-shouldered outside the country, we can actively explore the causes and discuss countermeasures, but we should avoid the anxiety and keep calm thinking. Literary works are both cosmopolitan and national, and their scope and extent of translation are limited. Promoting literature to go out is not a matter of improving the quality of English translation. It is a long-term process to cultivate the foreign readers of Chinese literature.

\section{References}

[1] Bao Xiaoying. Viewing the "going out" of Chinese literature from the translation effect of Mo Yanying's translation works [J]. Chinese translation, 2015, (1): 13 - 17.

[2] Fu Wenhui. English translation of Chinese female writers' works: literary translation, gender borrowing and Chinese image construction [J]. Foreign Languages, 2013, 36(5): 67 - 71.

[3] Gao Fang, Xu Wei. Current Situation, Problems and Suggestions_-Thoughts on the Going Out of Chinese Literature [J]. Chinese translation, 2010, (6): 5 - 9.

[4] Guo Jianling. Exotic vision: translation and acceptance of "Brothers" in the English world [J]. Literary Controversy, 2010, (12): 65 - 70.

[5] Hou Yu, Liu Zequan, Liu Dingjia. A Corpus-based Analysis of Ge Haowen's Translator's Style_- Taking the English Version of Mo Yan's Novels as an Example[J]. Foreign Language Research, 2014, (2): 72 - 78. 